\title{
Risk Factors of Prenatal and Postnatal Depression
}

\author{
Monica Kartini, Berlian Nurtyashesti Kusumadewi \\ Nursing Academy of Ngesti Waluyo, Temanggung, Central Java
}

\section{ABSTRACT}

Background: The postpartum period is the time when many women or mothers experience vulnerability to various psychological problems that can cause significant distress for them, especially postpartum depression (PPD). Therefore, it is important to do depression screening and assessment of risk factors for postpartum depression in pregnant women and new mothers. This study aimed to determine the incidence and biopsychosocial risk factors for postpartum depression.

Subjects and Method: This was a prospective cohort study conducted at Bulu, Kranggan, and Kedu health centers, in Temanggung, Central Java. A sample of 100 pregnant women with 3242 weeks gestation aged was selected for this study. The dependent variable was postpartum depression (PPD). The independent variables were marital satisfaction, symptoms of premenstrual syndrome, social support, general health status, and parenting self-efficacy/PSE. PPD was measured by the Edinburgh Postnatal Depression Scale. Parenting self-efficacy (PSE) was measured by the Karitane parenting confidence scale. The data were analyzed by Chi square.

Results: $5 \%$ of subjects have a severe risk of experiencing PPD. PSE was positively correlated with $\mathrm{PPD}(\mathrm{OR}=10.29 ; 95 \% \mathrm{CI}=1.20$ to 88.07; $\mathrm{p}=0.008$ ), while marital satisfaction, social support, premenstrual syndrome symptoms and general health status were not statistically significant with PPD incidence.

Conclusion: PSE increased the risk of PPD.

Keywords: post partum depression, parenting self-efficacy

\section{Correspondence:}

Monica Kartini. Nursing Academy of Ngesti Waluyo.Email: monica.kartini@gmail.com. Mobile: o81392445771.

Cite this as:

Kartini M, Kusumadewi BN (2020). Risk Factors of Prenatal and Postnatal Depression. J Epidemiol Public Healt. 05(01): 97-105. https://doi.org/10.26911/jepublichealth.2020.05.01.10

(c) (i) (2) Journal of Epidemiology and Public Health is licensed under a Creative Commons (c)

\section{BACKGROUND}

Postpartum or postnatal period is a period where many women or mothers experience vulnerability to various psychological problems, which can cause significant distress for mothers, disrupt family life, and if prolonged can affect the mental health of the mother and emotional development of children (Perry et al., 2014) One of the mental emotional problems associated with child birth is postpartum depression or post-partum depression (PPD). PPD is often defined as depression that occurs in the first year of the postpartum period. The risk factors for PPD as well as the symptoms of PPD are often not monitored during the examination and consultation of pregnant women and postpartum mothers. Halaris (2011) in (Stuart, 2013) states that one in ten clients who come to a primary health care center meets the criteria for major depressive disorder. However, primary health care providers unfortunately often fail to establish a diagnosis of severe depression in clients who can seek treatment by up to $50 \%$. This is one of the reasons for the importance of depression screening and assessment of PPD risk factors in pregnant women who come to primary care centers.

Depression screening in adults is very important to detect depression among wo- 
Kartini et al. / Risk factors of prenatal and postnatal depression

men of reproductive age, especially for those who have children or plan to become pregnant. This is because severe depression that occurs during pregnancy can have a negative impact on the fetus, neurocognitive disorders and the child's socio-emotional development and an increased risk of mental and physical disorders in offspring later in life (Bansil et al., 2010).

Knowing the risk factors during pregnancy will be able to help diagnose PPD and prevent the incidence of PPD or other psychological complications. Based on this background, this study was conducted by using the Edinburgh Postnatal Depression Scale (EPDS) to determine the incidence of PPD, as well as using other instruments to identify prenatal and postnatal risk factors for the incidence of PPD in pregnant women in Kranggan and Bulu health centers, in Temanggung Regency, Central Java.

\section{SUBJECTS AND METHOD}

\section{Study Design}

This study was conducted using a prospective cohort (longitudinal cohort study) method to investigate demographic, social, psychological and hormone-related risk factors in relation to the development of postpartum depression (PPD). The location of this research is in Temanggung Regency, namely in the working area of Bulu, Kranggan and Kedu Health center, Temanggung Regency, Central Java.

\section{Population dan Sample}

The subjects of this study were all pregnant women who had their pregnancies examined at Bulu, Kranggan and Kedu Health center, Temanggung Regency, Central Java. The inclusion criteria in this study were maternal gestation between 32-42 weeks and not undergoing therapy for psychiatric problems, while the exclusion criteria were mothers who could not read and write. The number of samples in this study were 100 respondents.

\section{Study Variables}

The dependent variable in this study is PPD. The independent variables are psychological, hormonal and psychosocial factors.

\section{Operational Definition of Variables} Postpartum depression is a change in function, mood, which causes depression or loss of interest as measured using the General Health Questionnaire (GHQ) instrument.

Factors related to hormones are mood changes before menstruation, and mood instability at puberty and premenstrual syndrome, which are measured using the Shortened Premenstrual Assessment Form (sPAF).

Psychosocial factors are social support that is measured by using the Social Support Appraisals Scale (SSA), marital relationship satisfaction as measured by Marital Inventory (ENRICH) and Parenting Self-efficacy (PSE) which are examined using the Karitane Parenting Confidence Scale (KPCS).

\section{Study Instruments}

PPD is measured using the Edinburgh Postnatal Depression Scale (EPDS) which has been translated into Indonesian. The Indonesian version of EPDS has been tested for validity and reliability (Hutauruk, 2011).

\section{Data Analysis}

The univariate analysis was carried out to describe each variables. Bivariate analysis was performed using Chi-square.

\section{Research Ethics}

This research was conducted after obtaining ethical approval from the Ethics Commission, namely the Ethics Commission of the Faculty of Medicine, Duta Wacana Christian University, Yogyakarta. Ethical clearance has been approved by obtaining an Ethical Clearance Certificate Number 619 / C.16 / FK / 2018.

\section{RESULTS}

1. Sample Characteristics

Demographic characteristics of the respondents are described in Table 1. 
Kartini et al. / Risk factors of prenatal and postnatal depression

Table 1. Sample Characteristics

\begin{tabular}{llcc}
\hline Characteristics & n & \% \\
\hline Number of children & 1 children & 36 & 36 \\
& 2 children & 50 & 50 \\
& 3 children & 11 & 11 \\
& 4 children & 2 & 2 \\
Maternal education & 6 children & 1 & 1 \\
& No formal education & 1 & 1 \\
& Primary School & 19 & 19 \\
& Junior high school & 41 & 41 \\
& Senior high school & 29 & 29 \\
Maternal Occupation & College & 10 & 10 \\
& Not working & 75 & 75 \\
& Working & 25 & 25 \\
& No formal education & 3 & 3 \\
& Primary School & 30 & 30 \\
& Junior high school & 31 & 31 \\
Living with husband & Senior high school & 32 & 32 \\
Family Income (Rupiah) & College & 4 & 4 \\
& Yes & 95 & 95 \\
& No & 5 & 5 \\
& $<1,500.000$ & 53 & 53 \\
& 1,500, ooo-3,ooo,ooo & 45 & 45 \\
\hline
\end{tabular}

2. Univariate analysis

a. Edinburg Postnatal Depression Scale (EPDS)

EPDS is an instrument filled in by the subject (self-report), consisting of 10 ques-tions that can be completed in less than 5 minutes. Each item is graded from o to 3 ("not at all" to "yes, very often") based on the severity of symptoms felt during the last week. Total scores were assessed with no risk of depression (o-8), moderate risk of depression (9-12) and risk of severe depression $(\geq 13)$ (Soep, 2011). Whereas Abdollahi et al. (2016) differentiate EPDS scores into two categories, namely not depressed (EPDS $\leq 12)$ and depression (EPDS $>12$ ).

In this study, of the 100 respondents, 80 of them did not have the risk of depression, 15 mothers at risk of being depressed and 5 subjects at risk of severe depression or were included in the category of depression. The average EPDS score is $4.8 \pm 4.20$ with a minimum score of $\mathrm{o}$ and a maximum score of
15 .

\section{b. Risk factors for depression}

The risk factors for post partum depression studied were parenting self-efficacy, marital satisfaction, social support, hormonal symptoms of premenstrual syndrome and general health status. The KPCS instrument was measured in conjunc-tion with the EPDS measurement, which was carried out two weeks post partum. While other factors are measured during the third trimester (prenatal) pregnancy. The results of each of these factors are written in the following Table 2.

Based on data from table 2 above, maternal parenting self-efficacy (PSE) is mostly good, where $46 \%$ of mothers show no clinical signs of parenting, and $26 \%$ in the range of mild clinical PSE, and as many as 8 mothers in the range of severe clinical PSE . Meanwhile, marital satisfaction data shows that a range of marital satisfaction that is evenly distributed between low, medium, high and very high marital satisfaction. Data 
Kartini et al. / Risk factors of prenatal and postnatal depression

on social support obtained during pregnancy shows that $50 \%$ of mothers get moderate social support, and the other 50\% has high social support, and no respondents report low social support.

Based on a history of premenstrual syndrome (PMS) experienced before preg- nancy, $4 \%$ of mothers said they did not experience PMS symptoms, and $22 \%$ of mothers reported severe PMS symptoms. While the general health status of respondents, almost 90\% of respondents are in moderate health status and only 1 subject has poor health status.

Table 2. Univariate Analysis (Continous Data)

\begin{tabular}{lccccc}
\hline Risk Factors & n & Mean & SD & Min. & Max. \\
\hline Parenting self-efficacy (KPCS) & 100 & 38.23 & 4.84 & 24 & 45 \\
Marital satisfaction (EMS) & 100 & 49.61 & 10.01 & 22.18 & 64.98 \\
Social support (SS-A) & 100 & 45.22 & 5.25 & 29 & 60 \\
Premenstrual syndrom/PMS (sPAF) & 100 & 23.28 & 8.39 & 10 & 49 \\
Health Status (GHQ) & 100 & 17.41 & 4.07 & 4 & 25 \\
\hline
\end{tabular}

Table 3. Univariate Analysis (Categorical Data)

\begin{tabular}{|c|c|c|c|}
\hline \multicolumn{2}{|c|}{ Risk Factors } & $\mathbf{n}$ & \% \\
\hline \multirow[t]{4}{*}{ Parenting Self-efficacy (KPCS) } & Non clinical range & 46 & 46 \\
\hline & Mild clinical range & 26 & 26 \\
\hline & Moderate clinical range & 20 & 20 \\
\hline & Severe clinical range & 8 & 8 \\
\hline \multirow[t]{4}{*}{ Marital satisfaction (EMS) } & Low & 22 & 22 \\
\hline & Moderate & 17 & 17 \\
\hline & High & 34 & 34 \\
\hline & Very high & 27 & 27 \\
\hline \multirow[t]{3}{*}{ Social Support (SS-A) } & Low & 0 & 0 \\
\hline & Moderate & 50 & 50 \\
\hline & High & 50 & 50 \\
\hline \multirow[t]{4}{*}{ Premenstrual syndrom/PMS (sPAF) } & Have no symptoms & 4 & 4 \\
\hline & Mild PMS symptoms & 34 & 34 \\
\hline & Moderate PMS Symptoms & 40 & 40 \\
\hline & Severe PMS symptoms & 22 & 22 \\
\hline \multirow[t]{3}{*}{ Health Status (GHQ) } & Good health status & 10 & 10 \\
\hline & Medium health status & 89 & 89 \\
\hline & Not good Health status & 1 & 1 \\
\hline
\end{tabular}

\section{The result of bivariate analysis}

The relationship between risk factors and post partum depression is summarized in Table 4.

Low parenting self-efficacy was positively and significantly correlated with PPD. Mothers with low PSE were ten times more likely to develop PPD $(\mathrm{OR}=10.29$; 95\% $\mathrm{CI}=$ 1.20 to 88.07). Dissatisfied marital function measured increased the risk of PPD but is not statistically significant $(R R=2.45 ; p=0.341)$.
Strong social support reduced the risk of PPD, but it was statistically non-significant $(\mathrm{OR}=0.947, \mathrm{p}=0.341)$.

Hormonal problems (measured by the severity of premenstrual syndrome before pregnancy) $(\mathrm{OR}=0.92, \mathrm{p}=0.755)$ and low maternal health status during pregnancy $(\mathrm{OR}=0.92 ; \mathrm{p}=0.141)$ decreased the risk of PPD, but they were statistically non-significant. 
Kartini et al. / Risk factors of prenatal and postnatal depression

Table 3. Risk Factors for Post Partum Depression

\begin{tabular}{lcccc}
\hline \multicolumn{1}{c}{ Risk Factors } & \multicolumn{2}{c}{ Depression Risk } & \multirow{2}{*}{ OR } & \multirow{2}{*}{ p } \\
\cline { 2 - 3 } & Yes & No & & \\
\cline { 1 - 2 } Parenting self-efficacy (KPCS) & & & & \\
Low & 4 & 24 & 10.286 & 0.008 \\
High & 1 & 71 & & \\
Marital satisfaction (EMS) & & & & \\
dissatisfied & 3 & 35 & 2.447 & 0.341 \\
satisfied & 2 & 60 & & \\
Social Support (SS-A) & & & & \\
Low & 5 & 89 & 0.947 & 0.270 \\
High & 0 & 6 & & \\
Hormonal, premenstrual syndrome (SPAF) & & & & \\
Severe & 3 & 59 & 0.919 & 0.755 \\
Mild & 2 & 36 & & \\
Public Health Status (GHQ) & & & & \\
Low & 2 & 40 & 0.921 & 0.141 \\
High & 3 & 55 & & \\
\hline
\end{tabular}

\section{DISCUSSION}

1. The relationship between parenting self-efficacy (PSE) and postpartum depression

Low parenting self-efficacy (PSE) increased the risk of post-partum depression $(\mathrm{OR}=$ 10.29; $\mathrm{p}=0.008)$. This result was supported by Choi et al. (2012), who explained that the low parenting self-efficacy affects the high incidence of postpartum depression. PSE in addition to correlating the incidence of depression in the mother also correlates with maternal anxiety and feelings of insecurity in a relationship.

Self-efficacy can be explained as an individual's beliefs about his ability to carry out a task well. Based on Bandura's theory, the perception of self-efficacy determines how much effort is given by individuals and how long they will hold up in facing challenges, which in turn will shape the affective response of individuals in dealing with stressful situations such as depressed mood (Bandura, 1997 in Haslam et al., 2006). The results show that people who have high self-efficacy are better and stronger when facing difficulties or challenges, become more positive, and more likely to be able to take productive actions and adaptive coping (Coleman and Kar- raker, 1997 in Haslam et al., 2006). So it can be understood that low PSE is correlated with negative effects, such as postpartum depression, maternal anxiety and attachment insecurity (Kohlhoff and Barnett, 2013).

2. The relationship between marital satisfaction and PPD

In this study, marital satisfaction did not show a significant correlation with the incidence of post partum depression $(p=0.341)$ although low marital satisfaction could increase the risk of PPD. This is contrary to the results of study by Kargar Jahromi et al. (2015) which shows that marital satisfaction has a correlation with the incidence of postpartum depression, indicated by as many as 40 out of 80 women as subjects of study were found to have post partum depression and as many as 24 women who experienced post partum depression showed low marital satisfaction. However, Lee and Hwang (2015) study found that only smoking behavior before pregnancy showed a significant correlation with the incidence of postpartum depression, while other factors including satisfaction of partner relationships did not correlate with PPD.

Anding et al. (2016) in his study getting stress experienced by a partner is the most 
Kartini et al. / Risk factors of prenatal and postnatal depression

powerful factor causing the emergence of postpartum depression in both father and mother. Satisfaction in a marital relationship is only related to postpartum depression in the father. Whereas in mothers, the condition of postpartum depression is related to life problems experienced, a history of violence experienced while still a child, and physical complaints after the delivery process. The absence of a significant correlation between marital satisfaction with the incidence of postpartum depression, according to the authors' assumptions is also influenced by Javanese cultural values which in this study were not observed by researchers. The husband and wife relationship in a Javanese family is unique. Couples in Javanese families have secrets that are always monitored in the context of positive thinking. The monitor glasses are called the culture of shame (isin). Embarrassment is the seed of positive individual thinking in the family. Isin and shy culture is the root of positive thinking in Javanese families. This isin culture that forms Javanese women not to tell their family secrets to others, because it is considered very embarrassing (Endraswara., 2017). The basic character of Javanese people is acceptance (nrima). Nrima is accepting everything with spiritual-psychological awareness, without grumbling (grumbling because of disappointment behind) (Endraswara., 2017).

\section{The relationship between social sup- port and post-partum depression}

Social support did not show a significant correlation with the incidence of post-partum depression in this study $(\mathrm{p}=0.270)$. This is contrary to Malus et al. (2016), which explains if the support of the couple in the relationship in marriage shows the significance of the incidence and development of postpartum depression. Closeness to the partner and intimacy in marriage, compatibility with the partner, and meeting the needs of the mother obtained in a marital relation- ship are related to the creation of good emotional conditions and coping mechanisms that are effective for mothers when facing labor difficulties, the presence of perineal wounds and newborn care.

Kusumastuti et al. (2015) also found that the support provided by the husband during the postpartum period showed a significant relationship to the incidence of postpartum depression. Mohammadi et al., (2011) study on 300 pregnant women also shows the result that there is a significant relationship between post partum depression condition in mothers with social support and with the adjustment of mothers in married life.

In this study, the absence of a significant correlation between social support and the incidence of postpartum depression can be caused by various things, for example because the process of collecting social support data is only done during the final trimester of pregnancy. Researchers did not measure social support to mothers during postpartum conditions. Measurement of social support for mothers during postpartum conditions is important to be able to know the significance of the relationship between social support in postpartum mothers for the incidence of postpartum depression, because during the postpartum period many physiological, psychological and role changes occur in mothers who really need support. One change in the mother is a change in sleep time and the role of the mother to take care of the child, especially at night. According to the study of Roomruangwong et al., (2011), mothers who did not get support to care for their babies at night were more likely to experience PPD.

The timing of social support in postpartum mothers was supported by research by Cheng et al. (2016). The study took respondents 1754 women in urban areas and city and village borders (VIVA project) and 877 women from community health centers 
Kartini et al. / Risk factors of prenatal and postnatal depression

(ACCESS projects) in Boston. In that study, social support was measured in the first trimester and mid-pregnancy. The results showed that the low support provided by the couple proved to be associated with high anxiety that occurs during pregnancy and depression during the mid-pregnancy period (on the ACCESS project). In the VIVA project, low partner support was also associated with depression in the middle of pregnancy and promoted maternal smoking behavior during pregnancy. So that social support variables should be measured on various time dimensions around pregnancy and postpartum.

\section{The relationship between premens- trual syndrome and postpartum de- pression}

The results of this study indicate that the symptoms of premenstrual syndrome are positively correlated but statistically not significant with postpartum depression.

This is supported by a study by Kepple et al. (2016) which shows that premenstrual dysphoric disorder (PMDD) does not show an association with postpartum depression (PPD). Stoner et al. (2017) in his study also found a strong relationship between premenstrual syndrome (PMS)/premenstrual dysphoric disorder (PMDD) with the condition of postpartum depression when measured on the fifth postpartum day, compared with measurements taken at 6 weeks and 6 months postpartum.

In this study, researchers measured premenstrual syndrome 2 weeks after postpartum. The measurement time criterion makes the authors assumptions about the reason for the absence of a significant correlation between premenstrual syndrome symptoms and post-partum depressive conditions.

\section{The relationship between general health status and postpartum dep- ression}

Based on the results of this study, the general health status of the mother did not show any significant correlation with the condition of postpartum depression in this study $(\mathrm{p}=$ 0.529). Papamarkou et al. (2017) showed that the condition of postpartum depression was independently related to the dimensions of physical function and the dimensions of physical discomfort. This shows that postpartum depression is significantly related to the general health dimension. Women with postpartum depression show low scores on the dimensions of body fitness.

In this study, measurements of maternal general health status were only carried out in prenatal conditions, so that the general health status of postpartum mothers was not measured in this study. Researchers assume if this results in the general health status of the mother it cannot be measured holistically to determine the correlation with the emergence of postpartum depression.

In this study, the incidence of PPD or mothers with a PPD risk of $5 \%$ by using an EPDS cut-off score $>12$ was obtained. From the risk factors studied, namely: PSE, marital satisfaction, social support, hormonal / premenstrual syndrome, and general health status, only Parenting Self-Efficacy (PSE) correlates significantly with PPD ( $\mathrm{p}=0.008)$, i.e. low PSE will increase depression tenfold compared with mothers who have high PSE $(\mathrm{RR}=10.29 ; \mathrm{p}=0.008)$, while other risk factors are not significantly correlated with PPD.

AUTHOR CONTRIBUTION
The main researcher is responsible for: pre-
paring a research proposal, arranging a re-
search permit, arranging a research ethics
permit, collecting research data, processing
data, preparing a final research report and
publishing research results. While the re-
search members are responsible for: collect-
ing research data, assisting thelead research-
er in processing data, assisting the lead re-
searcher in preparing the final report of the


Kartini et al. / Risk factors of prenatal and postnatal depression

study and publication.

CONFLICT OF INTEREST

There is no conflict of interest in this study

FUNDING AND SPONSORSHIP

The research was funded by the Kemenristekdikti's budding lecturer research grant for the 2018 fiscal year, with a contract number 105 / K6/KM/SP2H/RESEARCH/2018.

\section{ACKNOWLEDGEMENT}

The authors thank the Kemenristekdikti, research respondents, the Temanggung District Health Office, the Kedu Health center Midwife, Bulu Puskemas Midwife and Kranggan Health center Midwife.

\section{REFERENCES}

Abdollahi F, Zarghami M, Sazlina SG, Zain AM, Mohammad AJ, Lye MS (2016). 'Prediction of incidence and biopsychosocio cultural risk factors of post-partum depression immediately after birth in an Iranian population', Arch Med Sci, 12(5): 1043-1051. https://doi.org/10.5114/aoms.2016.58642.

Anding JE, Rohrle B, Grieshop M, Schucking B, Christiansen H (2016). 'Couple comorbidity and correlates of postnatal depressive symptoms in mothers and fathers in the first two weeks following delivery', J Affect Disord. Elsevier, 190: 300-309. https://doi.org/10.1016/j.jad.2015.10.033.

Bansil P, Kuklina EV, Meikle SF, Posner SF, Kourtis AP, Ellington SR, Jamieson DJ (2010). Maternal and fetal outcomes among women with depression, J Women's Health, 19(2): 329-334. https://doi.org/10.1089/jwh.2009.1387.

Cheng ER, Rifas SL, Perkins ME, Rich JW, Gillman MW, Wright R, Taveras EM (2016). The influence of antenatal partner support on pregnancy outcomes. $\mathrm{J}$
Women's Health, 25(7): 672-679. https://doi.org/10.1089/jwh.2015.5462.

Choi SY, Kim EJ, Ryu E, Chang KO, Park MN (2012). Postpartum depression and parental self-efficacy: A comparison of Native Korean and Vietnamese immigrant mothers in Korea. J Transcult Nurs, 23(2): 181-187. https://doi.org/10.1177/1043659611434057.

Endraswara S (2017). Berpikir Positif Orang Jawa. Yogyakarta: Pustaka Narasi.

Haslam DM, Pakenham KI, Smith A (2006). Social support and postpartum depressive symptomatology: the mediating role of maternal self-efficacy, Infant Ment, 27(3): 276-291. https://doi.org/10.1002/imhj.20092.

Hutauruk IS (2011). Indonesian version of the Edinburgh postnatal depression scale: Cross-cultural adaptation and validation. Jurnal Ilmiah Psikologi, 5(2). https://www.ejournal.gunadarma.ac.id/index.php/psiko/article/view/390.

Kargar JM, Zare A, Taghizadeganzadeh M, Rahmanian KA (2014). A study of marital satisfaction among nondepressed and depressed mothers after childbirth in Jahrom, Iran, 2014. Glob J health Sci, 7(3): 140-146. https://doi.org/10.5539/gjhs.v7n3p140.

Kepple A, Lee E, Haq N, Rubinow DR, Schmidt PJ (2016). History of Postpartum Depression in a Clinic-based Sample of Women with Premenstrual Dysphoric Disorder. J Clin Psychiatry, 77(4): 415420. https://doi.org/10.4088/JCP.15mo9779.

Kohlhoff J, Barnett B (2013). Parenting selfefficacy: Links with maternal depression, infant behaviour and adult attachment. Early Hum Dev, 89: 249-256. http://doi.org/10.1016/j.earlhumdev.2013.01.008.

Kusumastuti, Astuti DP, Hendriyati S (2015). Hubungan Karakteristik Individu de- 
Kartini et al. / Risk factors of prenatal and postnatal depression

ngan Depresi Postpartum pada Ibu Postpartum di Rumah Sakit Umum Daerah Kabupaten Kebumen (Relationship of Individual Characteristics with Postpartum Depression in Postpartum Mothers at the Kebumen District General Hospital). Jurnal Involusi Kebidanan, 5(9): 1-17. http://www.ejournal.stikesmukla.ac.id/index.php/involusi/article/download/57/53

Lee JY, Hwang JY (2015). A study on postpartum symptoms and their related factors in Korea. Taiwan J Obstet Gynecol. Elsevier Ltd, 54(4): 355-363. https://doi.org/10.1016/j.tjog.2014.04.030.

Malus A, Szyluk J, Galinska SB, Konarzewska B (2016). Incidence of postpartum depression and couple relationship quality. Psychiatr Pol, 50(6): 1135-1146. https://doi.org/10.12740/PP/61569.

Mohammadi A, Aghdam GA, Ranji S (2011) 'Comparison of postpartum depression of working women and housewives and its relationship with social support and marital adjustment. Procedia Soc Behav, 30: 1837-1839. https://doi.org/10.1016/j.sbspro.2011.10.354.

Papamarkou M, Sarafis P, Kaite CP (2017). Investigation of the association between quality of life and depressive symptoms during postpartum period: A correlational study. BMC Women's Health, 17(1): 1-9. https://doi.org/10.- 1186/s12905-017-0473-0.

Perry SE, Marlyn J, Hockenberry, Deitra LL, Lisa KL, David D, Cheryl AS (2014). Maternal Child Nursing Care. Fifth. Canada: Elsevier Mosby.

Roomruangwong C, Withayavanitchai S, Maes M (2016). Antenatal and postnatal risk factors of postpartum depression symptoms in Thai women: A case-control study. IJSHRH. Elsevier BV, 10: 25-31. https://doi.org/ 10.1016/j.srhc.2016.03.001.

Soep (2011). Penerapan Edinburgh Post-partum Depression Scale Sebagai Alat Deteksi Risiko Depresi Nifas pada Primipara dan Multipara (Application of Edinburgh Post-partum Depression Scale as a Detection Risk for Postpartum Depression in Primipara and Multipara). Jurnal Keperawatan Indonesia, 14(2): 95-100. http://jki.ui.ac.id/index.php/jki/article/view/315

Stoner R, Camilleri V, Calleja AJ, SchembriWP (2017). The cytokine-hormone axis-the link between premenstrual syndrome and postpartum depression', Gynecol Endocrinol, 33(8): 588-592. https://doi.org/10.1080/09513590.2017.1318367 .

Stuart G (2013). Principles and Practice of Psychiatric Nursing. St. Louis Missouri: Mosby. 